\title{
Developing a New Model for Evaluating Training and Capacity Building Outcomes in the Hospitality Industry
}

\author{
Yasser Ibrahim \\ Faculty of Tourism and Hotel Management, Helwan University
}

\begin{abstract}
Updating employees' skills and knowledge through continuous training and capacity building are becoming vital for any hospitality organization to remain competitive. Large amounts of resources are invested in training, however the results of such investment rarely evaluated by hospitality organizations due to the difficulty involved and the lack of valid and practical evaluation models. The purpose of this study is to present a new model for evaluating training and capacity building outcomes in the hospitality industry. The study tested the model with data collected using questionnaire from 203 hotel employees who participated in a training program aimed at improving competitiveness of the hospitality sector in the Red Sea Governorate. Structure equation modeling (SEM) was used to test the hypothesized relationships in the proposed model. Results of SEM confirmed the existence of a positive impact of capacity built during training on the organization, customers, employee and policy. The developed model offers a useful tool for conducting evaluations of training and capacity building activities in the hospitality industry.
\end{abstract}

Keywords: Training evaluation, capacity building, evaluation model

\section{Introduction}

In today's global tourism market, the capability of human resources is at the heart of every successful tourism destination. Training and capacity building must mirror international best practice and must work across the entire sector from service delivery to management. A feature of tourism, as in other modern economy industries, is that re-training and up-skilling must be a core part of human resource development planning (ENCC, 2013). The skills and knowledge of hospitality employees and continuous improvement through training are becoming vital for any hospitality organization to remain competitive (Dimitrov, 2012). Moreover, the success of the hotel business depends mainly on the technical and social skills of its staff. However, although the importance of human element within the hospitality industry, it is not appropriately developed and sometimes is considered as a low priority component within the industry (Ubeda-García et al., 2013). 
Training and capacity building activities are crucial for any business to build and sustain competitive advantage. These activities enhance productivity, efficiency and effectiveness of employees, innovation in the organization and hence competitiveness. The beneficiaries from these activities are not only individuals who may attend the training but also the customers of the organizations (Gordon \& Chadwick, 2007). Training is a key strategy for developing skills and knowledge in employees and that is why organizations invest in training. In Egypt for instance, the International Labour Organization (ILO) has been concerned about the problems facing the hospitality industry as skill gaps. It recognizes that in a "people" business like hospitality, developing a qualified workforce with the right set of aptitudes and attitudes will be essential. For these reasons, it implemented a series of training workshops aimed at improving competitiveness of hospitality sector in the Red Sea Governorate (ILO, 2015).

Holton (2005) argued that training is considered as an investment and therefore its actual impact to the organization's outcomes must be determined. He further indicated that evaluation is the key tool for this purpose as it is directly linked with the organization's quality systems. Moreover, Pineda (2010) added that the actual input made by training to the organization's outcomes must be determined through training evaluation. This evaluation helps in identifying training results and possible deficiencies, as well as introducing improvements to optimize the training function as a whole (Kirkpatrick \& Kirkpatrick, 2007).

Training professionals recognize that it is important and necessary to evaluate training; however such recognition does not translate into the implementation of rigorous evaluation systems that indicate the results of training (Pineda, 2010; Ubeda-García, 2013). Over the past years, a number of training evaluation frameworks have been developed with a wide range of possible instruments and tools used to evaluate training (Kirkpatrick \& Kirkpatrick, 2007; Tzeng et al., 2007; Pineda, 2010; Robson \& Sharon, 2014). However, the drawbacks of most of the training evaluation frameworks suggest that a new model is needed, which is practical and can be implemented within hospitality organizations. Therefore, the aim of this research is to develop and empirically test a new model for evaluating training and capacity building outcomes in the hospitality industry.

The first section of this paper is devoted to the theoretical review of training evaluation models that guide the formulation of the study conceptual framework and research hypotheses. The research methodology, including sampling and measures are presented in the second section. The final section of 
the paper is dedicated to the discussion of results as well as presenting the developed framework for evaluating capacity building and training activities.

\section{Literature Review}

Goldstein and Ford (2002) defined training evaluation as a systematic process of data collection to examine whether training really realized its intended purpose. Eseryel (2002) indicated that many training evaluation approaches could be identified such as the goal-free evaluation, goal-based evaluation, system evaluation, professional review and responsive evaluation. Usman and Jaedun (2016) claimed that the goal-based and system-based are the most commonly used methods for training evaluation. The goal-based approach is used with reference to Kirkpatrik's four-level evaluation, and the system-based approach is used with reference to CIRO model (contents/contexts, inputs, reactions and outcomes); CIPP model (context, input, process, product); and IPO model (input, process, output/outcomes). On the other hand, Mulhall (2015) explained that training evaluation models, depending on the philosophical approach chosen, can be divided into hierarchical or contextual. Hierarchical models such as Kirkpatrick's model and Phillip's ROI model are principally focused on the training outcomes for the organization, while contextual models such as CIPP and CIRO models incorporate a broader situational perspective.

Kirkpatrick's framework is the most widespread training assessment model used for assessing training outcomes in organizations for more than three decades. Kirkpatrick (1979) recognizes four levels of measures. The first level evaluates reaction to the training by participants. Level two named learning and it measures indicators of the learning that has followed throughout the training. Level three, known as behavior and addresses the degree to which skills and knowledge gained in training are used on the job. Finally level four, results are proposed to reveal the effect of training on organizational goals and objectives (Kirkpatrick \& Kirkpatrick, 2007; Passmore \& Velez, 2012). The model gained many of criticisms, for instance Guerci et al. (2010) argued that the model does not take into consideration the effects of the organizational context and, it assumes the viewpoint of the organization regardless the evaluation needs of all other stakeholders. Kaufman and Keller (1994) extended the four-level evaluation model with another level to reflect the internal and external consequences linked to performance and organizational enhancements as a result of training. However, Stokking (1998) indicated that it lacks clarity especially in the required sequences of activities. Passmore and Velez (2012) indicated that Phillips' ROI model has emerged with the introduction of ROI 
level to the Kirkpatrick model. The ROI dimension compares the financial training benefits with the cost of conducting the training (Phillips, 2007). However, Hogan (2007) claimed that it is hard to separate the effects of training from other organizational factors that can enhance performance.

An alternative and widely recited framework is the CIRO model proposed by Warr et al. (1970). The model evaluates training/learning efficiency before and after training. The CIPP is another model proposed by Stufflebeam in 1971 that has many common features with the CIRO framework (Stufflebeam, 2003; Roark et al., 2006). However with CIPP, the context offers situational data in order to define training activities objectives, input decides the strategies used to realize the outcomes, product involves the implementation of the training program and product also involves the assessment of the efficiency and effectiveness of outcomes (Khalid et al., 2012). However, these two models did not show how measurement takes place and are hard to implement in practice (Tzeng et al., 2007). Bushnell (1990) explained that the IPO model first studies input factors that may influence a training effectiveness. Then, it analyses process factors which includes the development and delivery of the program. Finally, it evaluates the short and long term results. Overall, the model was criticized for its shortage of data about the exact modules that influence the results (Robson \& Sharon, 2014). Holton (1996) proposed the human resources development evaluation model with three outcomes levels; i.e. learning, individual performance and organization. Then he recognized that the examination of the original model is difficult and proposed a modification of the model (Holton, 2005).

\section{Conceptual Framework for Evaluating Training and Capacity Building}

After critically review the most known models for evaluating training and capacity building activities, this study developed a framework to evaluate the impact of training activities. The framework depicted in Figure 1 aims to clarify and prove the linkages between the training programs delivered and the projected benefits using three level evaluations. Level one named capacity built that measures change at the individual trainee. This includes training that directly improves the knowledge, technical and managerial skills of individuals. Level two entitled capacity utilized that measures change at the organizational level. The change in practice or behavior subsequent the utilization of the new knowledge and skills in the form of efficiency, effectiveness and innovation in work environment that may take the form of training of other staff, better service delivery and improved communications. 
Finally, level three called training impact that measures impacts on the target stakeholder's behavior or practice. These impacts could be on employees, organization, customers and policy. In the hotel industry, these can be observable increase in customer satisfaction, improved occupancy rates, positive feedback from customers, increased job satisfaction, better working polices and improved employment conditions. Based on the proposed framework the following hypotheses were developed:

H1: Capacity built in individual trainee will have a positive effect on capacity utilized by the organization.

$\mathrm{H} 2$ : Capacity utilized by the organization will have a positive effect on employees, organization, customers and policy.

H3: Capacity built in individual trainee will have a positive effect on employees, organization, customers and policy.

H4: Capacity utilized by the organization mediates the relationship between capacity built in individual trainee and training impact.

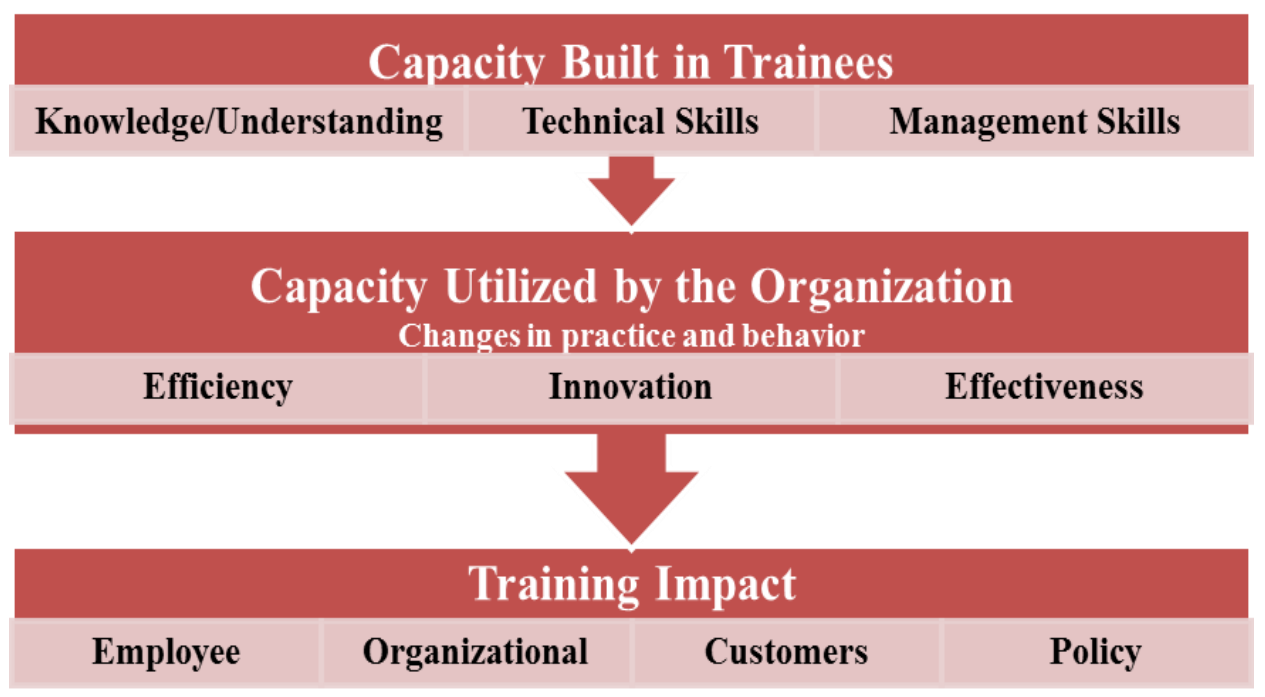

Figure 1: Framework for evaluating training and capacity building activities

\section{Methodology}

\subsection{Sample and Data Collection}

Data for this study was collected using a questionnaire from a sample of previous participants in the ILO hospitality training programs. The ILO project has implemented a series of training workshops aimed at improving competitiveness of hospitality sector. Each training workshop was delivered over five continues full training days during March and December 2015. Twenty one training workshops were conducted for a total of 435 participants 
from 74 hotels and resorts in the Red Sea Governorate. Stratified random sample was used in the current study. The population (435 training beneficiaries) is divided into 21 stratums representing all training workshops. The researcher received the lists of training beneficiaries from the ILO office in the Red Sea Governorate. Lists were used to identify the potential respondents for the questionnaire. Then simple random sampling was applied to each training group to select respondents. A sample size of 204 training beneficiaries was selected from the whole population based on 95\% confidence level and confidence interval 5 . In practice it is recommended that a study should aim at obtaining a 95\% confidence level that has a + or $-5 \%$ interval/error. The sample size is calculated using the following formula (Thompson, 2012):

$$
n=\frac{t^{2} \times p(1-p)}{d^{2}}
$$

$n=$ required sample size

$t=$ confidence level at $95 \%$ (standard value of 1.96)

$p=$ The approximate proportion of trained beneficiaries that are expected to be find in the hotels during the survey (in this case $50 \%$ )

$d=$ margin of error at $5 \%$ (standard value of 0.05 )

A number of 125 questionnaire forms completed via personal interview with training beneficiaries at the participated hotels in the Red Sea Governorate during August 2016. The rest of the sample was conducted via telephone interviews. The mean age of the respondents was 37 years while the minimum age was 24 years and the maximum was 58 years. In total, the majority of respondents (59\%) were between the ages of 31 and 40, followed by respondents aged between 41 to 50 years (24\%), followed by respondents aged between 25 to $30(11 \%)$. A small proportion of respondents (4\%) was above 50 years old, and only $2 \%$ of respondents were under 25 years old. The age distribution of respondents clearly shows that the training activities addressed the supervisory and managerial levels of staff. Males were dominant among the total trainees with $96 \%$ of all participants. This result is expected as very low representation of women in the tourism workforce especially in hotel positions in the Red Sea region due to location. Regarding the educational level of respondents, the majority of respondents $(69 \%)$ have university degree and only $31 \%$ of the respondents have technical high school degree. This is a normal result due to that the project addressed in this activity the supervisory and managerial level of hotel staff. 


\subsection{Research Instrument}

The questionnaire used in this study was divided into two sections; the first section addressed demographic variables. The second section asked employees about their evaluation of the capacity built due to training (11 items), capacity utilized by the organization (12 items), and the impact of training on personal development, customer, organization and policy (14 items). A 5-point Likert scale was employed in all scales. The developed questionnaire was pilot tested with a sample of 30 training beneficiaries by phone and following pre-testing, minor amendments were made. The result of reliability test revealed that all Cronbach's $\alpha$ exceeded the standard value of 0.7 suggested by Hair et al. (2010). The final questionnaire items are listed in Table 1 along with their means and standard deviations. The content validity was assessed by five experts in the field of hotel management. Consequently, it is concluded that all scales used are acceptably valid and reliable.

\section{Results}

The collected data was analyzed using SPSS and AMOS software. The two stage approach was employed in this study to evaluate the measurement model (Anderson \& Gerbing, 1988). Composite reliability (CR) and Cronbach's $\alpha$ were used to test the construct reliability. Hair et al. (2013) indicated that a factor loading of 0.40 is considered appropriate for a sample size of 200 to ensure a high significance factor level. Consequently it was decided that 0.40 is appropriate for the sample size $(\mathrm{N}=203)$ of the present study. The proportion of mediation test and the Sobel test were also conducted.

\subsection{Reliability and Validity Analyses}

All the parcels under the constructs loaded on a single factor explaining more than $50 \%$ of total variance for each factor. The Cronbach's $\alpha$ values for the parcels ranged between 0.864 and 0.922, which exceed the 0.70 recommended acceptable reliability coefficient (Hair et al., 2010). This reported high Cronbach's $\alpha$ values demonstrating a highly reliable unidimensional construct, this was also supported by the exploratory factor analysis (EFA) results. Moreover, for all parcels the percentage of variance explained was more than $50 \%$, which is also acceptable according to the conventional threshold criteria for Cronbach's $\alpha$, composite reliability (CR) and for the average variance extracted (AVE). Consequently, all these parcels were entered into confirmatory factor analysis (CFA). 
Table 1 The study constructs, sub constructs and measurement items

\begin{tabular}{|c|c|c|c|}
\hline Construct & Measurement items & Mean & $S D$ \\
\hline \multicolumn{4}{|c|}{ Capacity Built $\quad$ Cronbach's $\alpha=.92$} \\
\hline \multirow{4}{*}{ Knowledge } & The training provided me with new relevant knowledge & 4.50 & .47 \\
\hline & I better understand international trends/activities in my field & 4.41 & .58 \\
\hline & knowledge gained enabled me to interpret new policies and procedures & 4.35 & .64 \\
\hline & I gained knowledge about current issues in the hospitality industry & 4.44 & .49 \\
\hline \multirow{3}{*}{$\begin{array}{l}\text { Technical } \\
\text { skills }\end{array}$} & I acquired new technical skills & 4.43 & .51 \\
\hline & I learned new analysis skills & 4.37 & .66 \\
\hline & I gained new skills in identifying KPI related to my work & 4.36 & .65 \\
\hline \multirow{4}{*}{$\begin{array}{l}\text { Management } \\
\text { skills }\end{array}$} & I learned new methods to solve work problems & 4.39 & .56 \\
\hline & I gained techniques for organizing and managing people and projects & 4.29 & .72 \\
\hline & I gained skills in developing human resources in my department & 4.41 & .71 \\
\hline & I acquired improved ways to communicate effectively & 4.43 & .58 \\
\hline \multicolumn{4}{|c|}{ Capacity Utilized Cronbach's $\alpha=.92$} \\
\hline \multirow{5}{*}{ Efficiency } & I work more efficiently after training & 4.45 & .49 \\
\hline & My competency and confidence in work was increased & 4.43 & .61 \\
\hline & The training helped me to perform better & 4.41 & .44 \\
\hline & $\begin{array}{l}\text { I trained other staff in my hotel on the knowledge and skills gained } \\
\text { through training }\end{array}$ & 4.29 & .52 \\
\hline & My manager assigned me work where I used the new skills I learned & 4.19 & .74 \\
\hline \multirow{2}{*}{ Innovation } & I was able to initiate my own project/work activities & 4.15 & .65 \\
\hline & My hotel became innovative and prepared to fund new methodologies & 4.16 & .66 \\
\hline \multirow{5}{*}{ Effectiveness } & $\begin{array}{l}\text { I increased my professional understanding of new trends in the } \\
\text { hospitality industry both nationally and internationally }\end{array}$ & 4.27 & .49 \\
\hline & The quality of work discussions in my department has improved & 4.30 & .61 \\
\hline & $\begin{array}{l}\text { The developed policies by the organization are well informed about } \\
\text { potential impact }\end{array}$ & 4.28 & .59 \\
\hline & The training has enhanced the management practises of the organization & 4.31 & .55 \\
\hline & I better use my analytical thinking due to training & 4.31 & .47 \\
\hline \multicolumn{4}{|c|}{ Training Impact Cronbach's $\alpha=.86$} \\
\hline \multirow{5}{*}{ Personal } & This training had no impact on my work situation* & 3.89 & .61 \\
\hline & Training enabled me to move to another position (promotion) & 3.65 & .82 \\
\hline & My work situation changed for the better due to the training & 4.09 & .63 \\
\hline & The training motivated me to take part in other training activities & 4.26 & .79 \\
\hline & My new level of knowledge and skills was rewarded by my employer & 4.05 & .86 \\
\hline \multirow{5}{*}{ Organization } & The training had no impact on the hotel performance $*$ & 2.02 & 1.3 \\
\hline & The hotel has changed significantly for the better due to the training & 3.90 & .91 \\
\hline & The hotel improved employment conditions due to the training & 3.78 & .82 \\
\hline & The training motivated the hotel to perform more training activities & 4.01 & .88 \\
\hline & Job turn over decreased after training & 3.97 & .93 \\
\hline \multirow{2}{*}{ Customers } & Customer satisfaction has increased as a result of this training & 4.10 & .74 \\
\hline & Customer positive feedback has increased as a result of this training & 3.94 & .89 \\
\hline \multirow{2}{*}{ Policy } & $\begin{array}{l}\text { The knowledge acquired from the training supported me to influence } \\
\text { hotel and company policies }\end{array}$ & 3.72 & .94 \\
\hline & $\begin{array}{l}\text { The training increased the hotel's ability to influence policy decisions } \\
\text { made by local authority or government }\end{array}$ & 3.50 & .97 \\
\hline
\end{tabular}




\subsection{CFA Results for Constructs}

A second-order measurement model of Capacity Built, Capacity Utilized and Training Impact was tested. The results showed that all items loaded highly on their respective factors and the chi-square analyses showed that the twocomponent model of the constructs provided the best fit to the data (Hair et al., 2013). All the constructs had acceptable levels of CR, ranging from 0.898 and 0.914, and the AVE was more than .50 (Fornell \& Larcker, 1981). In addition, all Cronbach's $\alpha$ values exceeded the recommended value of 0.7 demonstrating that the instrument is reliable (Bagozzi \& Yi, 1988). Also, composite reliability values were all greater than the recommended value of more than 0.7 . Three parcels were created in EFA analysis and used as indicators of Capacity Built (the latent construct). These parcels were labeled knowledge, technical skills, and management skills. Three parcels were representing Capacity Utilized; efficiency, innovation and effectiveness. Four parcels were used as indicators of Training Impact; personal, customers, policy and organizational. Table 2 illustrates the final confirmatory factor analysis (CFA) results of the models. The indicators had high $t$-values significant at $p<0.001$, and the standardized factor loadings were between 0.802 and 0.935. Moreover, the AVE and the CR met the minimum requirements.

Table 2 Internal consistency estimates and CFA results of constructs.

\begin{tabular}{|c|c|c|c|c|c|c|}
\hline Construct & Sub Construct & \begin{tabular}{|l|} 
Number \\
of items
\end{tabular} & SFL* & $\mathbf{C R}^{*}$ & AVE* & $\alpha^{*}$ \\
\hline \multirow{3}{*}{ Capacity Built } & Knowledge & 4 & 0.816 & \multirow[t]{3}{*}{0.898} & \multirow[t]{3}{*}{0.746} & \multirow[t]{3}{*}{0.922} \\
\hline & Technical Skills & 3 & 0.867 & & & \\
\hline & Management Skills & 4 & 0.905 & & & \\
\hline \multirow{3}{*}{ Capacity Utilized } & Efficiency & 5 & 0.935 & \multirow[t]{3}{*}{0.914} & \multirow[t]{3}{*}{0.780} & \multirow[t]{3}{*}{0.917} \\
\hline & Innovation & 2 & 0.854 & & & \\
\hline & Effectiveness & 5 & 0.858 & & & \\
\hline \multirow{4}{*}{ Training Impact } & Personal & 5 & 0.814 & \multirow[t]{4}{*}{0.908} & \multirow[t]{4}{*}{0.711} & \multirow[t]{4}{*}{0.864} \\
\hline & Organizational & 5 & 0.871 & & & \\
\hline & Customers & 2 & 0.802 & & & \\
\hline & Policy & 2 & 0.883 & & & \\
\hline
\end{tabular}

*SFL, standardized factor loading; CR, composite reliability; AVE, average variance extracted; $\alpha$, Cronbach's $\alpha$ coefficient

Confirmatory factor analysis (CFA) was conducted for the dimensions with their subdimensions, a second-order analysis for the constructs of Capacity Built, Capacity Utilized and Training Impact was conducted as well. The results showed that the overall CFA and all the AVE were close and more than 
the recommended value 0.5 . In addition, the construct reliability for all the dimensions was more than 0.7. These loadings confirmed that the items were loaded satisfactory on their constructs. The CFA results support the unidimensionality within each parcel, which were acceptable according to the conventional threshold criteria of 0.7 for Cronbach's $\alpha, 0.7$ for composite reliability and 0.5 for AVE (Hair et al., 2013). It can be concluded that all constructs exhibited good internal consistency. Consistent with the orientation of the study which is based on parceling the variables, the CFA results exhibited that the second order model gave better fit to the data. The intercorrelations between the two factor models were significant $(p<0.001)$. Goodness of fit was found to be good. Further, the results showed that all items loaded highly on their respective factors. All critical ratio values exceeded the minimum guideline of 1.96 , with all values significant at the 0.001 levels, and all the item loadings were more than twice their standard error. Moreover, discriminant validity and divergent validity were confirmed. All mean values for the scales were more than the midpoint of the scale. Data collected mirror that the total mean score of Capacity Built is 4.39 (SD, .47) led to Capacity Utilized with mean score of $4.32(S D, .49)$ and Training Impact with mean score of $3.64(S D, .61)$ see Table 3 .

Table 3 Means, standard deviations and inter construct correlations.

\begin{tabular}{|c|c|c|c|c|c|}
\hline Variables & Mean & $S D$ & 1 & 2 & 5 \\
\hline 1. Capacity Built & 4.39 & 0.47 & 0.864 & & \\
\hline 2. Capacity Utilized & 4.32 & 0.49 & $0.652^{* *}$ & 0.883 & \\
\hline 3. Training Impact & 3.64 & 0.61 & $0.478^{* *}$ & $0.650^{* *}$ & 0.843 \\
\hline
\end{tabular}

\subsection{Structural Model and Testing Research Hypotheses}

Structure equation modeling (SEM) was used to test the hypothesized relationships in the model (Hair et al., 2013). Fig. 2 shows the path coefficients for the model and their significance. .It also shows that the estimated structural model and the estimated standardized path coefficients were good bases for testing the hypothesized relationships among the constructs. The $x^{2}$ statistic indicated an adequate fit with the data $\left(x^{2}=116.678 ; \mathrm{df}=54 ; \mathrm{p}<.001\right)$. The positive and statistically significant standardized path coefficients support the 
relationships among the constructs. The fit indices indicated that the structural model had a good fit with the data, $\left(x^{2} / \mathrm{df}=2.161\right.$; GFI $=.921$; CFI $=.988$; TLI $=.983 ;$ RMSEA $=.076)$, fulfilling the respective benchmarks, and supporting the proposed hypothetical framework of the study (Bagozzi \& Yi, 1988; Hair et al., 2013). Thus, it could be concluded that Capacity Built has both direct and indirect effects on Capacity Utilized and Training Impact.

As shown in Fig. 2, all the hypothesized relationships are supported for the estimated structural model. The results suggested that the relationship between Capacity Built and Capacity Utilized was positive and statistically significant as it was hypothesized ( $t$-value $=11.303, \beta=0.72, p<0.001$ ). The results, demonstrated positive and significant path from Capacity Utilized to Training Impact ( $t$-value $=6.228, \beta=0.57, p<0.001)$. The results also revealed that the relationship between Capacity Built and Training Impact was positive and statistically significant ( $t$-value $=2.306, \beta=0.2, p<0.05$ ). Thus, $\mathrm{H} 1, \mathrm{H} 2$ and H3 were supported. The Sobel test (Sobel, 1982), was used to test the mediating role of Capacity Utilized in the linkage between Capacity Built and Training Impact in the SEM model. The result of the Sobel test showed significance $(Z=4.438$, Standard Error $=.092, p<0.001)$, supporting the mediation effect, that Capacity Utilized partially mediates the relationship between Capacity Built and Training Impact. Thus, H4 was supported.

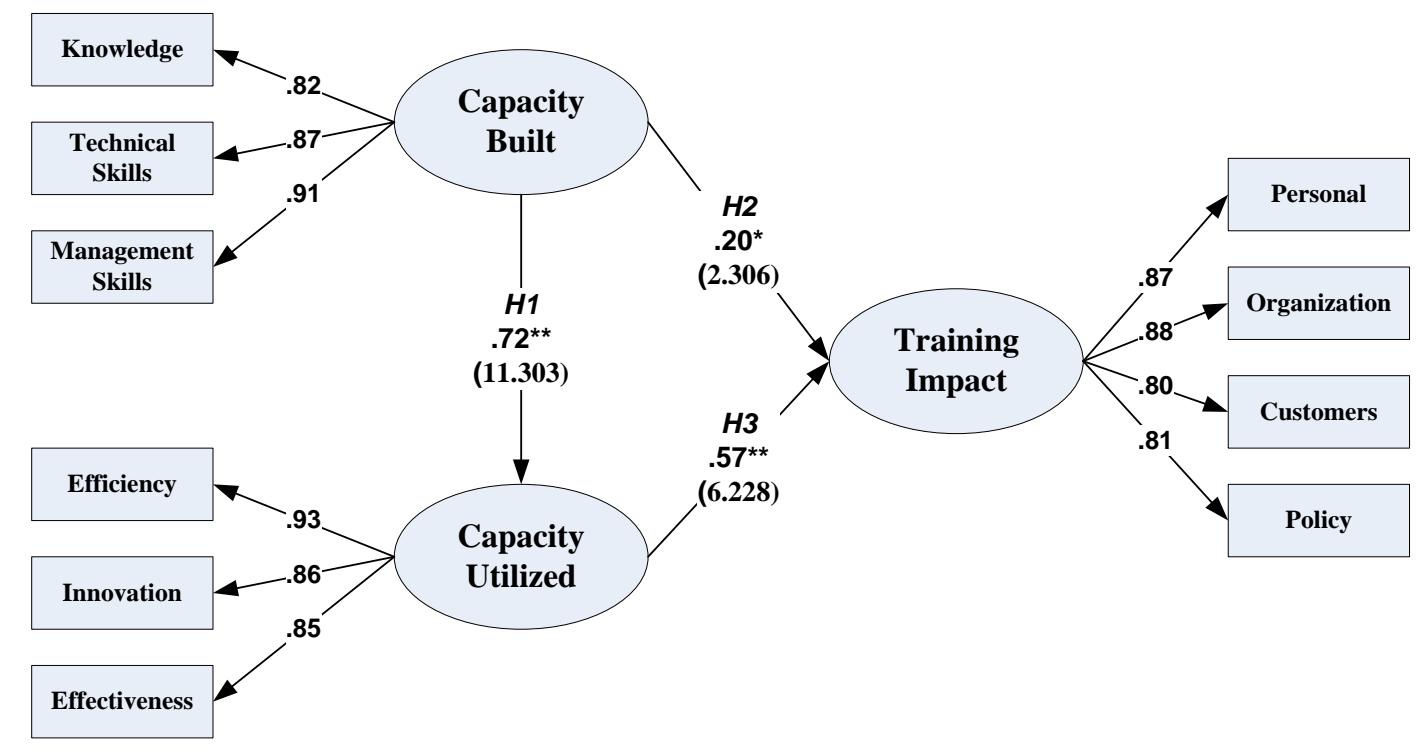

Note: the figure within parentheses () is $t$-value, $*$ denotes $p<0.05$, ** denotes $p<0.001, x^{2}=116.678$, $\mathrm{df}=54, x^{2} / \mathrm{df}=2.161, \mathrm{GFI}=.921, \mathrm{CF}=.988, \mathrm{TLI}=.983, \mathrm{RMSEA}=.076$

Fig.2 Path diagram of research model shows the relationships between capacity built, capacity utilized and training impact. 


\section{Conclusions and Limitations}

\subsection{Conclusions}

The study offered and empirically validated a new model for evaluating training and capacity building activities in the hospitality industry. The model was tested with data collected from 203 training beneficiaries of the ILO hospitality training in the Red Sea Governorate. The model uses three level evaluations namely; capacity built, capacity utilized and training impact. The first level measures change at the individual trainee level. The second level measures change at the organizational level. The third level measures impacts on the target stakeholder's behavior or practice.

This study proved the existence of a positive impact of capacity built during training on the organization, customers, employee and policy in the hospitality industry. Also, the study has contributed to identifying the mediating factor that contributes to the existence of the aforementioned correlation. The analytical results support the four proposed hypotheses. The results revealed that the capacity built in individual trainees positively affects the capacity utilized by the organization and consequently has positive impacts on employees, organization, customers, and policy. These results conform to previous studies evaluating the impact of training for instance; Barret and O'Connell (2001) found that general training positively affect productivity. Guerrero and Barraud-Didiere (2004) proved that training positively affects quality and profitability. Ubeda-Garcia (2005) found that training led to increased sales per employee, employee satisfaction, customer satisfaction and owner/shareholder satisfaction. Many studies revealed that training has positive effects on labor productivity, staff turnover, competence and commitment of staff, absenteeism and value added by worker (Cho et al., 2006; Zheng et al., 2006; Ghebregiorgis \& Karsten, 2007). In summary, Skills development of hospitality employees is clearly a critical part of the strategic solution for improving competitiveness of the sector through decent work. To be effective, training must be responsive to the changing requirements of the sector.

The developed model can be used to assess the impact of training on organizational performance. Training evaluation methods used by hospitality organizations should not only assess the design and methodology of the training course and the knowledge gained as a result of training but also to include other factors as the long term impact of the training. The impact factors should be an integral part of the evaluation process; such as applying the knowledge gained to the workplace, the impact of training on working conditions, as well as the effects of training on the short and long term organizational development. 


\subsection{Limitations and Future Research}

The approach taken in this study has some limitations. For example, because of the underlying interacting relationships between characteristics, the direct relationships presented in the model may need to be further verified with new data and different research techniques. The future research can replicate the study on a larger sample frame of employees and the model needs to be tested in different hospitality settings.

\section{References}

Anderson, J.G. \& Gerbing, D.W. (1988). Structural Modeling in Practice: A Review and Recommended Two-step Approach. Psychological Bulletin, 103 (3), 411-423.

Bagozzi, R.P. \& Yi, Y. (1988). On the Evaluation of Structural Equation Models. Journal of the Academy of Marketing Science, 16 (1), 74-94.

Barrett, A. \& O'Connell, P.J. (2001). Does Training Generally Work? The Returns to In-company Training. Industrial and Labor Relations Review, 54, 647-662.

Bushnell, D. (1990). Input, Process, Output: A Model for Evaluating Training. Training and Development Journal, 44 (3), 41-43.

Cho, S., Woods, R.H., Jang, S. \& Erdem, M. (2006). Measuring the Impact of Human Resource Management Practices on Hospitality Firm's Performances. International Journal of Hospitality Management, 25, 262-277.

Dimitrov, D. (2012). Sources of meaningfulness in the workplace: A study in the US hospitality sector. European Journal of Training and Development, 36 (2/3), 351-371.

ENCC (Egyptian National Competitiveness Council) (2013). Refreshed Tourism Strategy 2013-2020 The Way Forward and New Horizons. Retrieved 1 February 2017 from: http://www.encc.org.eg.

Eseryel, D. (2002). Approaches to Evaluation of Training: Theory and Practice. Educational Technology and Society, 5 (2), 93-99.

Fornell, C. \& Larcker, D.F. (1981). Evaluating Structural Equation Models with Unobservable Variables and Measurement Error. Journal of Marketing Research, 18 (3), 39-50.

Ghebregiorgis, F. \& Karsten, L. (2007). Human resource management and performance in a developing country. International Journal of Human Resource Management, 18, 321-332.

Goldstein, I.L. \& Ford, J.K (2002). Training in Organization: Needs Assessment Development and Evaluation (4 ${ }^{\text {th }}$ ed.). Wardsworth. 
Gordon, J. \& Chadwick, K. (2007). Impact Assessment of Capacity Building and Training: Assessment Framework and Two Case Studies. Impact Assessment Series Report No. 44, the Australian Centre for International Agricultural Research.

Guerci, M., Bartezzaghi, E. \& Solari, L. (2010). Training Evaluation in Italian Corporate Universities: A Stakeholder-based Analysis. International Journal of Training and Development, 14 (4), 291-308.

Guerrero, S. \& Barraud-Didiere, V. (2004). High-involvement practices and performance of French firms. International Journal of Human Resource Management, 15, 1408-1423.

Hair, J. F., Black, W. C., Babin, B. J. \& Anderson, R. E. (2010). Multivariate Data Analysis: A global perspective, $7^{\text {th }}$ ed., London: Pearson.

Hair, J.F., Hult, G.T.M., Ringle, C.M. \& Sarstedt, M. (2013). A Primer on Partial Least Squares Structural Equation Modeling, (PLS-SEM). Thousand Oaks: Sage Publications.

Hogan, R.L. (2007). The Historical Development of Program Evaluation: Exploring the Past and Present. Online Journal of Workforce Education and Development, 2(4), 1-14.

Holton, E. (1996). The Flawed Four-level Evaluation Model. Human Resource Development Quarterly, 7 (1), 5-21.

Holton, E. (2005). Holton's Evaluation Model: New Evidence and Construct Elaborations. Advances in Developing Human Resources, 7 (1), 37-54.

International Labour Organisation (2015). ILO Tourism Activities in Egypt. Retrieved 1 March 2017 from: http://www.ilo.org.

Kaufman, R. \& Keller, J. M. (1994). Levels of Evaluation: Beyond Kirkpatrick. Human Resource Development Quarterly, 5 (4). 371-380.

Khalid, M., Rehman, C. \& Ashraf, M. (2012). Exploring the Link Between Kirkpatrick (KP) and Context, Input, Process and Product (CIPP) Training Evaluation Models, and its Effect on Training Evaluation in Public Organizations of Pakistan. African Journal of Business Management, 6 (1), 274-279.

Kirkpatrick, D. (1979). Techniques for Evaluating Training Programs. Training and Development Journal, 78-92.

Kirkpatrik, D.L. \& Kirkpatrick J.D. (2007). Implementing the Four Levels: A Practical Guide for Effective Evaluation of Training Programs. San Francisco: Berrett-Koehler Publishers.

Mulhall, S. (2015). Evaluating HRD Programmes. In Carbery, R. \& Cross, C. (Eds), Human Resource Development: A Concise Introduction, Macmillan, Hampshire, Palgrave. 
Passmore, J. \& Velez, M. (2012). SOAP-M: A training Evaluation Model for HR. Industrial and Commercial Training, 44 (6), 315-325.

Phillips, J.J. (2007). Strategy for Implementing ROI in HR and Training. Oxford, UK: Library Catalog Pub.

Pineda, P. (2010). Evaluation of Training in Organisations: A Proposal for an Integrated Model. Journal of European Industrial Training, 34 (7), 673-693.

Roark, S., Kim, M. \& Mupinga, M. (2006). An Exploratory Study of the Extent to which Medium-sized Organizations Evaluate Training Programs. Journal of Business and Training Education, 15, 15-20.

Robson, F. \& Sharon, M. (2014). Evaluating Training and Development in UK Universities: Staff Perceptions. European Journal of Training and Development, 38(6), 553-569.

Sobel, M.E. (1982). A Symptotic Intervals for Indirect Effects in Structural Equation Models. Social Methodology, 13 (1), 290-312.

Stokking, K. (1998). Levels of Evaluation: Kirkpatrick, Kaufman and Keller, and Beyond. Human Resource Development Quarterly, 7 (2), 179-183.

Stufflebeam, D.L. (2003). The CIPP Model for Evaluation. International Handbook of Educational Evaluation, 9, 31-62.

Thompson, S. K. (2012). Sampling. $3^{\text {rd }}$ ed., John wily \& Sons, New Jersey.

Tzeng, G., Chiang, C. \& Li, C. (2007). Evaluating Intertwined Effects in Elearning Programs: A Novel Hybrid MCDM Model Based on Factor Analysis and DEMATEL. Expert Systems with Applications, 32, 1028-1044.

Ubeda-Garcia, M. (2005). Training and Business Performance: the Spanish Case. The International Journal of Human Resource Management, 16 (9), 1691-1710.

Ubeda-García, M., Marco-Lajara, B., Sabater-Sempere, V., García-Lillo, F. (2013). Does Training Influence Organisational Performance?: Analysis of the Spanish Hotel Sector. European Journal of Training and Development, 37 (4), 380-413.

Usman, H. \& Jaedun, A. (2016). Impact-based Training Evaluation Model (IBTEM) For School Supervisors in Indonesia. International Education Studies, 9 (2), 149-165.

Warr, P., Bird, M. \& Rackham, N. (1970). Evaluation of Management Training: A Practical Framework, with Cases, for Evaluating Training Needs and Results. Gower Press: London.

Zheng, C., Morrison, M. \& O’Neill, G. (2006). An Empirical Study of High Performance HRM Practices in Chinese SMEs. International Journal of Human Resource Management, 17, 1772-1803. 


\section{الملخص العربى}

\section{تطوير نموذج جديد لتقييم نتائج التدريب وبناء القدرات فى صناعة الضيافة}

يعد تحديث مهارات العاملين فى منظمات الضيافة من خلال التدريب المستمر أمراً حيوياً لكي نظل

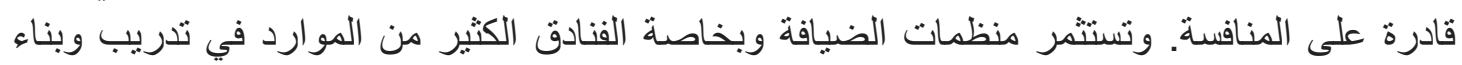

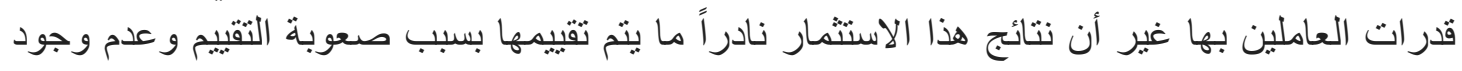

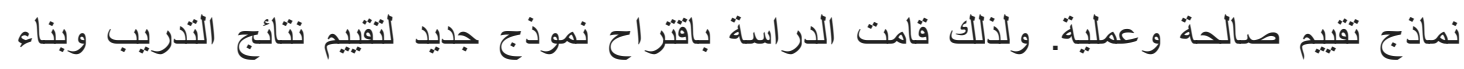

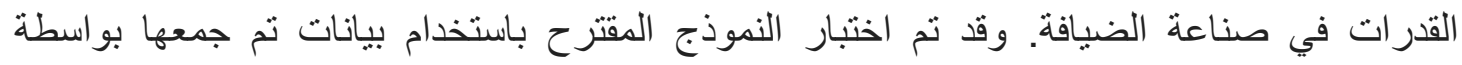

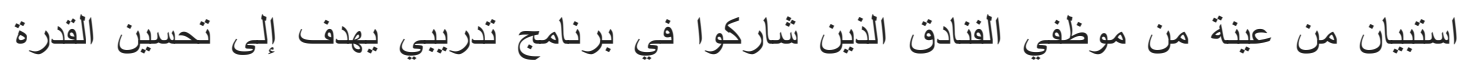
التنافسية لقطاع الضيافة في محافظة البحر الأحمر. وقد أظهر التحليل الإحصائى لبيانات الإستبيان

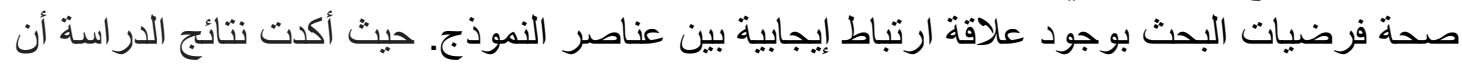

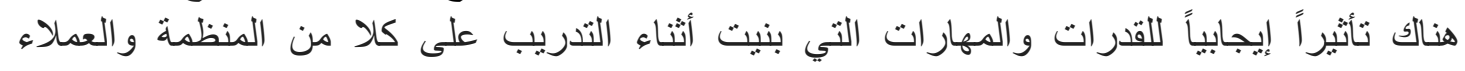

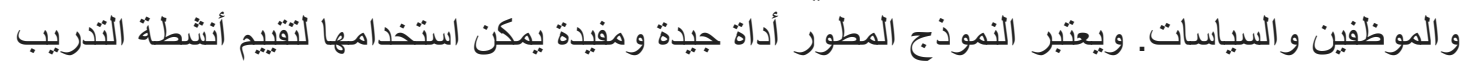
وبناء القدر ات في قطاع الضيافة. 